\title{
Effects of Scaling Up Family Planning on Maternal Survival in Ethiopia: Spectrum Modeling
}

\author{
Abebaw Wasie Kasahun' \\ Haimanot Abebe Adane (ID) \\ Tadele Girum' \\ Wako Golicha Wako ${ }^{2}$ \\ 'Department of Public Health, Wolkite \\ University, Wolkite, Southwest Region, \\ Ethiopia; ${ }^{2}$ School of Public Health, Bule \\ Hora University, Bule Hora, South \\ Region, Ethiopia
}

Background: Ethiopia has made great strides on under-five and maternal mortality reduction as demonstrated by achieving the millennium development target of child mortality reduction by the start of 2015 . According to a recent demographic and health survey report, Ethiopia has a 67 per 1000 under-five mortality rate and a 412 per 100,000 live births maternal mortality ratio. The current trend of maternal and child mortality reduction is not enough to meet sustainable development goal three (SDG3) of maternal and child mortality reduction target which is set to reduce the maternal mortality ratio to below 70/100,000 live births in all countries. This paper aimed to model the effect of scaling up family planning on pregnancies, live births, stillbirths, abortions and maternal mortality in Ethiopia.

Methods: We used the Spectrum software package to model the impact of family planning on maternal survival and other maternal health metrics. Spectrum has different modules consisting of demproj module (demographic projection), famplan module (family planning), LiST (life saved tool), and AIM (aids impact model). We used Demproj, Famplan and LiST modules for this particular paper. Baseline national data were taken from findings of the Ethiopian demographic and health survey 2016, and World Bank and World Health Organization country specific reports.

Results: Total fertility rate will decline to 2.3 children per women by the year 2030 when contraceptive prevalence is scaled up by $2 \%$ annually from 2016 to 2030 . As a result of continuous scaling up of contraceptive use, around 3.17 million unintended pregnancies can be averted. Unmet need for family planning will significantly decline to $11.7 \%$ by 2030 . Ninety-four thousand unsafe abortions could be averted and 1233 additional maternal lives could be saved by the end of 2030 in Ethiopia.

Conclusion: Scaling up family planning has shown a significant effect to meet the SDG3 maternal mortality reduction target. A considerable proportion of unintended pregnancies and unsafe abortions can be averted by scaling up contraceptive prevalence by $2 \%$ annually until 2030. Family planning is effective and a less costly intervention to reduce maternal mortality in countries with high fertility; hence, it is highly recommended to rampup all efforts to scale up contraceptive use for improving maternal health status in Ethiopia.

Keywords: family planning, maternal survival, spectrum modeling, Ethiopia

\section{Background}

Family planning has a significant contribution for maternal and child mortality reduction. However, considerable proportions of women are not using effective contraceptive methods despite the demand for family planning. As a result unintended pregnancy, unsafe abortion and associated deaths are high. ${ }^{1}$ In the era of sustainable development goals, there is a need to scale up impactful interventions more than ever before to save the lives of women and children. ${ }^{2}$ The international community calls for family planning to be at the epicenter of sustainable
Correspondence: Abebaw Wasie Kasahun Email abebawasie@gmail.com 
development goals; because family planning has the potential to achieve almost all the sustainable development goals in one way or another. ${ }^{3}$

In line with sustainable development goals, the family planning 2020 program aspired to enable women and girls to freely decide whether, when and how many children to have. According to the family planning 2020 program an additional 120 million women and girls are expected to have access to rights-based family planning services and supplies by $2020 .{ }^{4}$ Family planning impacts eradication of poverty and hunger, increasing access to universal education, promoting gender equality, reduction of maternal and child mortality as well as environmental sustainability. ${ }^{5}$ Birth spacing through increased use of family planning can save more than 2 million children and newborn lives every year. ${ }^{6}$ Scaling up family planning could prevent onethird of maternal deaths by allowing women to delay motherhood, avoid unintended pregnancies and subsequent abortions. ${ }^{7}$ Global countries have reached a consensus to reduce the maternal mortality ratio to less than 70 per 100,000 live births and to reduce under-five mortality below 25 per 1000 live births. ${ }^{8}$

Ethiopia has made great strides on under-five and maternal mortality reduction as demonstrated in achieving the millennium development target of child mortality reduction at the start of $2015 .^{9,10}$ According to a recent demographic and health survey report, Ethiopia has 67 per 1000 under-five mortality rate and 412 per 100,000 live births maternal mortality ratio. ${ }^{11}$ The current trend of maternal and child mortality reduction is not enough to meet sustainable development goal three (SDG3) of maternal and child mortality reduction targets. Currently, only $36 \%$ of married women are using contraceptives in Ethiopia. However, 58\% of married women have demand for family planning in Ethiopia, from this it can be noted that $22 \%$ of married women have an unmet need for family planning. ${ }^{11}$

According to the revised reproductive health strategy of Ethiopia, the country is committed to reduce unmet need for family planning to below $10 \%$, increase contraceptive prevalence rate to $55 \%$ and to reduce total fertility rate to 3 children by the year $2020 .^{12}$ To achieve the national targets, potential impactful prospective interventions must be generated and communicated to convince all stakeholders to take collaborative action. Therefore, this study aimed to model the effects of scaling up family planning on maternal health indicators in Ethiopia.

\section{Methods}

Projection analysis was done on maternal health indicators for the years 2016 to 2030 in Ethiopia. Two scenarios were created for each model year about contraceptive prevalence rate. The first scenario was keeping contraceptive prevalence rate constant from 2016 to 2030 whereas the second scenario is scaling up contraceptive rate by $2 \%$ annually from 2016 to 2030 .

Interactive Spectrum software modules namely Demproj, famplan and LiST software packages were used to project the impact of scaling up contraceptive use on demographic events, maternal survival and other maternal health indicators in Ethiopia.

Bongaarts proximate determinant of fertility framework was used to analyze the effect of changes in contraceptive use on total fertility. According to Bongaarts proximate determinants of fertility framework, fertility is affected by factors consisting of marriage, contraception, postpartum insusceptibility, sterility, induced abortion and total fecundity. ${ }^{13,14}$ According to Bongaarts, total fertility is estimated using the formula shown below:

TFRt $=1 / 4$ Cmt $\times$ Cit $\times$ Cat $\times$ Cst $\times$ Cet $\times$ TF

Where:

$\mathrm{t}=$ subscript denoting time

$\mathrm{TFR}=$ total fertility rate

$\mathrm{Cm}=$ marriage index

$\mathrm{Ci}=$ postpartum insusceptibility index

$\mathrm{Ca}=$ abortion index

$\mathrm{Cs}=$ sterility index

$\mathrm{Cc}=$ contraception index

$\mathrm{TF}=$ total fecundity: Total fecundity is the average number of births a woman would have during her entire reproductive age if there are no factors acting to inhibit fertility.

Postpartum insusceptibility is a measure of the inhibiting effect of breastfeeding or abstinence on fertility in the population. The famplan module of Spectrum software is developed based on the Bongaarts proximate determinants fertility framework.

\section{Data Sources}

Data regarding proximate determinants of fertility were taken from the Ethiopian demographic and health survey 2011 report. $^{15}$

Basic maternal and child health services coverage including antenatal care, postnatal care, skilled birth, immunization and others were obtained from the 2016 EDHS report. Total population of Ethiopia with age structure is taken from the central statistical agency which is automatically loaded in 
Spectrum software. Baseline information for maternal mortality ratio, child mortality rate, contraceptive prevalence rate and total fertility rate were obtained in the EDHS 2016 report. ${ }^{11}$ We used baseline maternal mortality ratio of 412/ 100,000 live births, baseline total fertility rate of 4.1 , baseline contraceptive prevalence of $36 \%$, and baseline unmet need for family planning was taken as $22 \%{ }^{11}$

\section{Data Analysis}

Data analysis was done using Spectrum software. Data analysis was done twice. Firstly, base case analysis was done keeping all baseline variables constant to the year 2030. Secondly, another analysis was done by assuming consistent increment of contraceptive prevalence rate by $2 \%$ annually from 2016 to 2030 in Ethiopia. Finally, the changes on maternal health indicators were computed by subtracting results of respective maternal health indicators on the two analyses. For example, additional maternal lives saved were obtained by subtracting maternal deaths averted due to contraceptive use at baseline contraceptive prevalence rate from maternal deaths averted after contraceptive prevalence rate has scaled up. Potential life years gained is also calculated by multiplying numbers of additional maternal lives saved by reproductive age life expectancy which is 27 years.

\section{Results}

Contraceptive prevalence rate would be $64 \%$ and total fertility rate will decline to 2.3 children per woman by the year 2030 in Ethiopia. The trend in fertility reduction from 2016-2030 is shown in Figure 1 below.

Unmet need for family planning among married women will decline to $11.7 \%$ in 2030 from $22 \%$ in 2016 . Unmet need for family planning at each year from 20162030 is presented in Table 1 below.

Contraceptive users will increase to more than 14 million by 2030 . Contraceptive users were little more than 5 million in 2016 in Ethiopia. About 3.17 million unintended pregnancies would be averted from 2016-2030 in Ethiopia as shown in Figure 2.

Seventy-eight thousand maternal deaths and 94,000 unsafe abortions can be averted by 2030 as shown in Figure 3 .

From the total of 78,000 maternal deaths that would be averted by 2030, 1233 averted maternal deaths are attributed to the $2 \%$ continuous increment in contraceptive use from 2016-2030 in Ethiopia. The potential life years gained as a result of increased use of contraceptive is 33,291 person years by 2030 .

\section{Discussion}

Ethiopia is a country with very poor maternal health metrics. As a result, the national government and nongovernmental organizations are working on the identification and execution of different impactful strategies for better maternal health. Family planning is a strategy that has been put in place to improve maternal and child health all over the world including Ethiopia. This study attempts

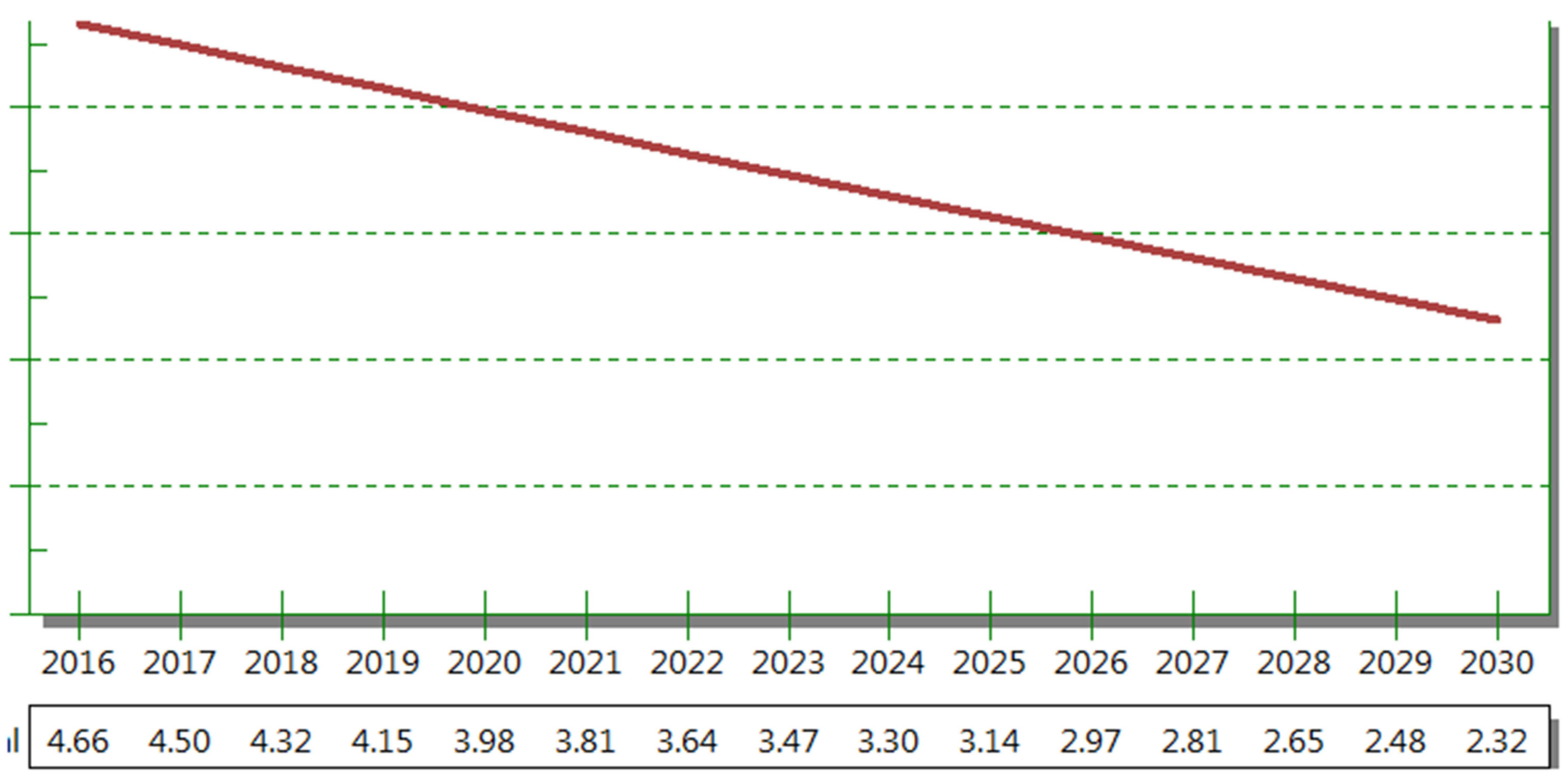

Figure I Total fertility rate projection from 2016 to 2030 in Ethiopia. 
Table I Unmet Need for Family Planning Among Married Women from 2016-2030 in Ethiopia

\begin{tabular}{|l|l|l|l|}
\hline Year & Unmet Need & Year & Unmet Need \\
\hline 2016 & 22 & 2024 & 17.2 \\
2017 & 21.7 & 2025 & 16.4 \\
2018 & 21.2 & 2026 & 15.5 \\
2019 & 20.7 & 2027 & 14.6 \\
2020 & 20.1 & 2028 & 13.6 \\
2021 & 19.5 & 2029 & 12.7 \\
2022 & 18.8 & 2030 & 11.7 \\
2023 & 18 & & \\
\hline
\end{tabular}

to depict the impact of scaling up contraceptive use on maternal health metrics including number of additional maternal lives saved, unintended pregnancies, unsafe abortions, unmet need for family planning, total fertility rate and potential life years gained among reproductive age women in Ethiopia from 2016-2030. According to this projection unmet need for family planning will decline to
$11.7 \%$ by 2030 in Ethiopia and thereby 3.17 million unintended pregnancies would be avoided from 2016-2030 in Ethiopia. This result depicts that the sustainable development target to reduce maternal mortality ratio to less than 70 per 100,000 live births is within reach if strong political and health system willingness to scale up contraceptive use is in place. ${ }^{4}$

The total fertility rate will fall to 2.3 children per woman by the year 2030 from the current total fertility rate of 4.6 children in Ethiopia. ${ }^{11}$ This would enable Ethiopia to have a good demographic dividend and would in turn boost the national economy. This would be due to the fact that reducing fertility will enable women to join the labour force, furthermore it will reduce the dependency ratio, decreasing school dropout among girls, and it decreases maternal and child care cost. For every dollar invested in family planning an estimated US\$1.4 can be saved that would be spent on maternal and child care in addition an estimated US\$ can be saved that would be

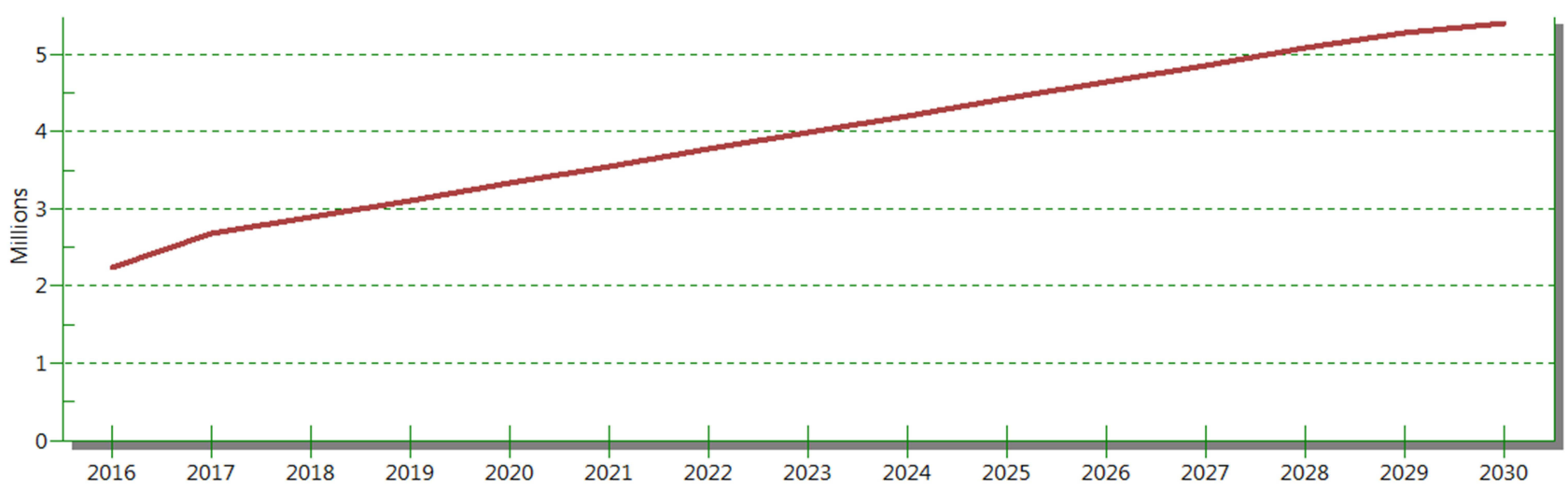

Figure 2 Number of unintended pregnancies that would be averted due to modern contraceptive method use in Ethiopia from 2016 to 2030.
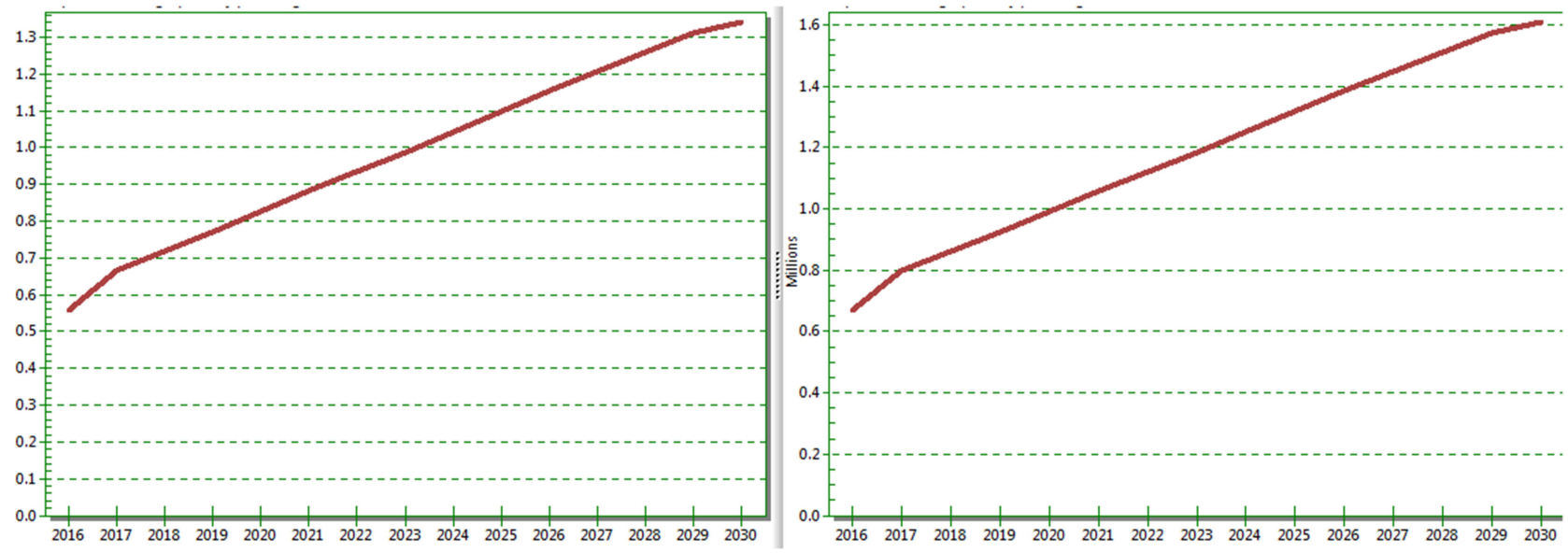

Figure 3 Number of maternal deaths and unsafe abortions that would be averted due to contraceptive use in Ethiopia from 2016 to 2030 . 
spent on treating complications of unintended pregnancies. ${ }^{16}$ In Nigeria, reducing total fertility rate by one child per woman would bring $13 \%$ increment in GDP in 20 years and $25 \%$ increment in 50 years. ${ }^{16}$

According to this analysis 94,000 unsafe abortions can be averted from 2016-2030 in Ethiopia. Maternal morbidity and mortality attributable to abortion is very high in Ethiopia, ${ }^{17}$ hence reducing the above-mentioned number of potential abortions will significantly contribute for maternal survival and healthy life.

This projection shows that 1233 additional maternal lives can be saved by scaling up family planning from 2016-2030 in Ethiopia. Similarly, there are reports from South Africa and Sierra Leone that show scaling up family planning could save maternal lives. ${ }^{1,18}$

This study is not without limitations, there are several limitations that readers should bear in mind. The projection is done using a marital index of the country so it does not consider those who are sexually active but not married. So, the projected estimates do not represent all women in the reproductive age group. In addition, the data for contraceptive prevalence is for the entire reproductive age group, it would have been more informative if contraceptive use was known across different age groups, because the effect of contraceptive use among extreme age groups is not similar to middle aged women in relation to maternal mortality. The spectrum analysis does not appreciate the impact of birth spacing on maternal survival, as a result it is more likely to underestimate the benefit of family planning to maternal survival. This analysis is done keeping the effect of all other factors and maternal health care interventions constant.

\section{Conclusion}

This projection has shown that a significant number of maternal lives can be saved by scaling up contraceptive use. Though it demands concerted efforts on government and nongovernmental organizations to expand the logistics and accessibility of family planning services, unmet need for family planning, unintended pregnancy and unsafe abortion can be significantly reduced. The analysis has demonstrated that the national target for reducing unmet need for family planning is within reach by keeping the greatest commitment for expanding the service by all stakeholders in place.

\section{Abbreviations}

Demproj, Demographic projection working feature on spectrum; Famplan, Family planning working feature on
Spectrum; LiST, Life saved tool (intervention impact assessment feature on Spectrum); SDG, Sustainable development goal.

\section{Data Sharing Statement}

Full data set and other materials pertaining to this study can be obtained from corresponding author on reasonable request.

\section{Ethics Approval and Consent to Participate}

Ethical clearance was obtained from institutional ethical review board of Wolkite University.

\section{Consent for Publication}

Not applicable.

\section{Acknowledgment}

We would like to acknowledge Wolkite University for arranging a scientific venue for review and approval of this research project.

\section{Author Contributions}

All authors contributed to data analysis, drafting and/or revising the article, gave final approval of the version to be published, and agreed to be accountable for all aspects of the work.

\section{Funding}

No fund received.

\section{Disclosure}

The authors declare that they have no competing interests.

The abstract of this paper was presented at Family Planning and Comprehensive Post Abortion Care: Strengthening pre-service training Conference in Addis Ababa as a poster presentation with interim findings in April 4-5, 2019. The poster's abstract was published in https://cirht.med.umich.edu/abstracts/

The abstract of this paper was submitted and accepted for oral presentation on 31st Ethiopian Public Health Association annual research conference in Addis Ababa as oral presentation with interim findings in 2020 but the conference was cancelled due to COVID 19 pandemic. The abstract was published in https://www.etpha.org/con ference/index.php/31stConference/31stConference/paper/ $\underline{\text { view/2957 }}$ 


\section{References}

1. Chola L, McGee S, Tugendhaft A, Buchmann E, Hofman K. Scaling Up Family Planning to Reduce Maternal and Child Mortality: the Potential Costs and Benefits of Modern Contraceptive Use in South Africa. PLoS One. 2015;10(6):e0130077. doi:10.1371/journal. pone. 0130077

2. Chopra M, Daviaud E, Pattinson R, Fonn S, Je. L. Saving the lives of South Africa's mothers, babies, and children: can the health system deliver. Lancet. 2009;374(9692):835-846. doi:10.1016/S01406736(09)61123-5

3. Petruney T, Wilson LC, Stanback J. Family planning and the post-2015 development agenda. Bull World Health Organ. 2014;92:548. doi:10.2471/BLT.14.142893

4. International Planned Parenthood Federation: sustainable Development Goals and Family Planning 2020; 2016.

5. Cates W Jr. Family planning: the essential link to achieving all eight Millennium Development Goals. Contraception. 2010;81(6):460-461. doi:10.1016/j.contraception.2010.01.002

6. Rutstein SO. Effects of preceding birth intervals on neonatal, infant and under-five years mortality and nutritional status in developing countries: evidence from the demographic and health surveys. Int $j$ Gynaecol Obstet. 2005;89.

7. Collumbien M, Gerressu M, Cleland J. Non-use and use of ineffective methods of contraception. Comparative quantification of health risks: global and regional burden of disease attributable to selected major risk factors. World Health Organization; 2004.

8. World Bank Group. World Development Indicators; 2016. Available from http://datatopics.worldbank.org/world-development-indicators /user-guide.html. Accessed July 1, 2021.
9. Ruducha J, Mann C, Singh NS, et al. How Ethiopia achieved Millennium Development Goal 4 through multisectoral interventions: a Countdown to 2015 case study. Lancet Global Health. 2017;5(11): e1142-e1151. doi:10.1016/S2214-109X(17)30331-5

10. World Health Organization. Success Factors for Women's and Children's Health; 2015.

11. Central statistical agency. Ethiopian demographic and health survey report; 2016.

12. Federal Democratic Republic of Ethiopia Ministry of Health: national Reproductive Health Strategy; 2016.

13. Stover J. Revising the proximate determinants of fertility framework: what have we learned in the past 20 years? Stud Fam Plann. 1998;29 (3):255-267. doi: $10.2307 / 172272$

14. Bongaarts J. A framework for analyzing the proximate determinants of fertility. Popul Dev Rev. 1978;4(1):105. doi:10.2307/1972149

15. Central statistical agency: ethiopian demographic and health survey report; 2011.

16. Africa Union: Family Planning and the Demographic Dividend in Africa. Policy Brief for the International Conference on Maternal, Newborn and Child Health (MNCH) in Africa Johannesburg, South Africa; 2013.

17. Mekonnen W, Hailemariam D, Gebremariam A. Causes of maternal death in Ethiopia between 1990 and 2016: systematic review with meta-analysis. Ethiop J Health Dev. 2018;32(4).

18. Keen S, Begum H, Friedman HS, James CD. Scaling up family planning in Sierra Leone: a prospective cost-benefit analysis. Women's Health. 2017;13(3):43-57.

\section{Publish your work in this journal}

The International Journal of Women's Health is an international, peerreviewed open-access journal publishing original research, reports, editorials, reviews and commentaries on all aspects of women's healthcare including gynecology, obstetrics, and breast cancer. The manuscript management system is completely online and includes a very quick and fair peer-review system, which is all easy to use. Visit http://www.dovepress.com/testimonials.php to read real quotes from published authors. 